\title{
Yellow nail syndrome; a well documented condition but missed for many years due to unknown reasons
}

\author{
Ranasinghe KNP, Jayasinghe P, Wijesinghe S, Amarabandu P, De Silva H, \\ Base Hospital Tangalle, Sri Lanka.
}

Correspondence:

Dr. KNP Ranasinghe

e-mail: nilanther@yahoo.com

\section{Case Report}

A 77-year-old labourer was admitted to medical ward at Base Hospital Tangalle with bilateral leg swelling of one week duration. He had repeated hospital admissions to other hospitals over the last twenty years for chronic cough, breathlessness and wheezing and had several diagnosis cards issued for chronic obstructive pulmonary disease, bronchial asthma pneumonia and bronchiectasis. Pulmonary tuberculosis has been excluded on three occasions but there was no regular clinic follow-ups.

$\mathrm{He}$ had no history of ischaemic heart disease, hypertension or diabetes. Patient had attended school only up to $3^{\text {rd }}$ grade and had a very poor socialeconomical background.

On general examination his upper limb nails were dystrophic, yellowish (Figure 1) and both legs were swollen (non pitting oedema) up to the thighs (Figure 2). He had bilateral basal crepitations and ronchi. Air entry was less in the right lung base. His cardiovascular, abdominal and central nervous system examinations were unremarkable.

Routine investigations including ECG, full blood count, serum creatinine, electrolytes, blood urea, $\mathrm{TSH}$, serum albumin and liver function tests were normal. He had a normal 2D echo with ejection fraction of $45 \%$. Three sputum samples were negative for acid fast bacilli (AFB).

His chest radiograph showed a moderate right sided pleural effusion (Figure 3 ) and $400 \mathrm{ml}$ straw coloured clear fluid was aspirated. It showed, protein; $6.4 \mathrm{~g} / \mathrm{dL}$, sugar; $146 \mathrm{mg} / \mathrm{dL}, \mathrm{LDH} ; 303 \mathrm{u} / \mathrm{L}$, amylase; $44 \mathrm{u}$, Red Blood Cells $650 / \mathrm{mm}^{3}$, leucocytes $1042 / \mathrm{mm}^{3}$ with $80 \%$ lymphocytes and was negative for malignant cells and AFB. Ultrasound examination showed a small $(4.4 \mathrm{~cm})$ echogenic right kidney and normal $(9.7 \mathrm{~cm})$ left kidney and no other abnormalities or ascites.

There was no cause detected for his pleural effusion or lymphoedema and the diagnosis of Yellow nail syndrome was made in the presence of the typical triad of yellowish discolouration of nails, pleural effusion and lymphoedema with recurrent attacks of bronchitis or bronchiectasis.

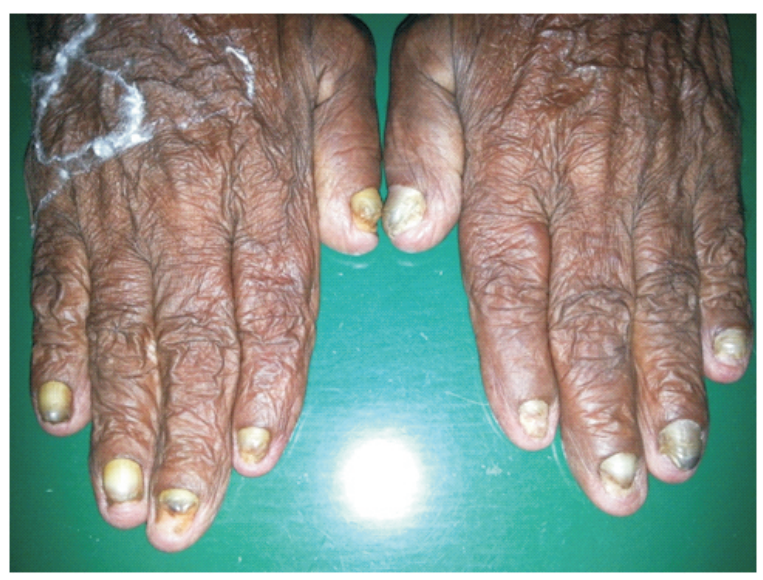

Figure 1: Dystrophic,yellowish nails

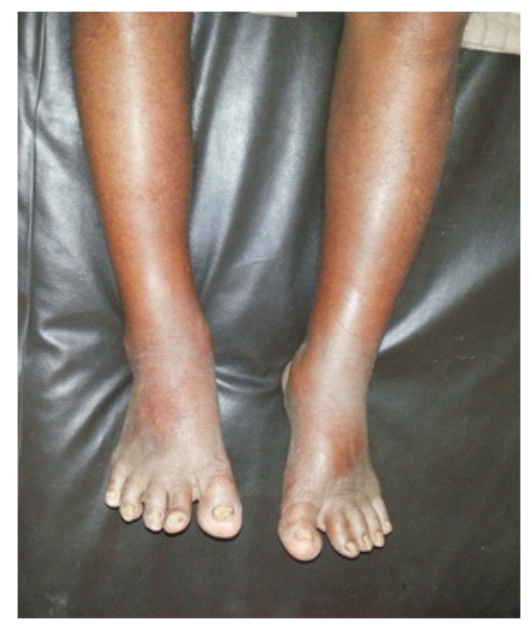

Figure 2: Bilateral non pitting oedema of legs 


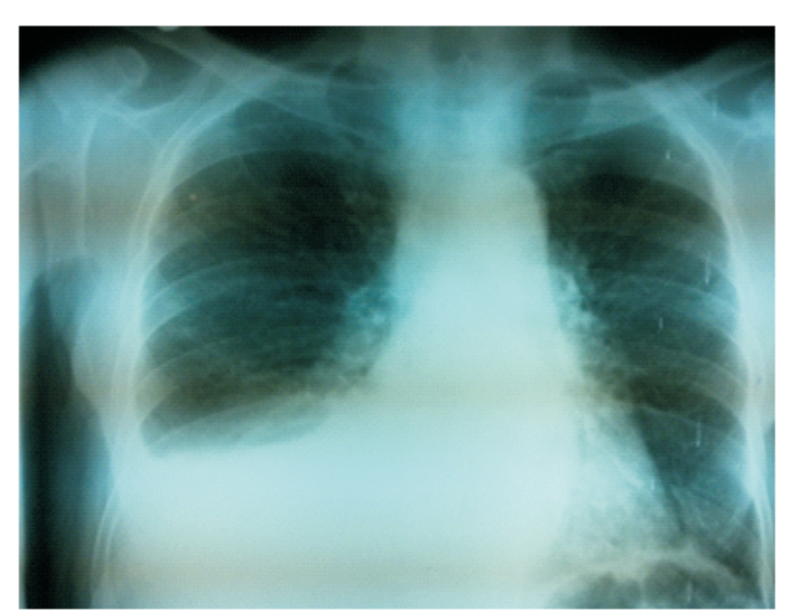

Figure 3: Pleural effusion of right side

\section{Discussion}

The Yellow nail syndrome is a very rare disease with a typical tirade of yellow nails, lymphoedema and pleural effusions (1). Typically, the nails are slowgrowing, thick and dystrophic with a yellowish discolouration and there may be onycholysis (2). It is commonly associated with recurrent respiratory problems such as bronchitis, bronchiectasis recurrent pneumonia and sinusitis $(1,2)$. It is usually acquired later in life but there may be congenital cases. Most of these signs coexist simultaneously, but usually develop at different stages of life as seen in our patient. As different clinical features of the syndrome may occur at wide intervals patients may not present with the classical triad of symptoms (2). Our patient has been suffering from chronic respiratory problems over the last 20 years with multiple hospital admissions. Although he had a yellowish nail discolouration it remained unnoticed due to the coexisting fungal infection. Typically yellow nails are seen in both limbs but this patient only presented with upper limb involvement.
His pleural effusion and lymphoedema developed most recently and simultaneously. All common causes for pleural effusion and oedema were excluded before arriving at this diagnosis. As seen in this patient non pitting leg swelling (lymphoedema) occurs more than $80 \%$ but there may be hands, facial and genital involvements (3). Pleural effusions are commonly exudates and are predominant with lymphocytes (3). The etiology of this syndrome is unknown and management is largely symptomatic (4). There are other reported associations of this condition such as chylous ascites, intestinal lymph-angiectasia, thyroid abnormalities, malignancies; immunological abnormalities and rheumatoid arthritis $(2,5)$. Our patient had unilateral contracted small kidney.

\section{References}

1. Riedel M. Multiple effusions and lymphoedema in the yellow nail syndrome. Circulation, 2002; 105(3): E25-6.

2. Hillerdal G. Yellow nail syndrome: treatment with octreotide. The Clinical Respiratory Journal, 2007; 1(2): 120-1. doi: 10.1111/j.1752-699X.2007.00022. [published Online First: Epub Date].

3. Valdes L, Huggins JT, Gude F, et al. Characteristics of patients with yellow nail syndrome and pleural effusion. Respirology, 2014. doi: 10.1111/resp.12357. [published Online First: Epub Date].

4. Liptrot S, Hulks G, Roberts F. Early pulmonary manifestations of yellow nail syndrome: a case report. Virchows Archiv: An International Journal of Pathology 2007; 451(5): 985-6. doi: 10.1007/s00428-007-0503-7 [published Online First: Epub Date].

5. Gunnarsson O, Bjornsson E, Bjornsdottir US, Gudbjartsson T. [Yellow nail syndrome]. Laeknabladid, 2007; 93(11): 751-3. 